\title{
Temperature-mediated changes in microbial carbon use efficiency and ${ }^{13} \mathrm{C}$ discrimination
}

\author{
Christoph A. Lehmeier ${ }^{1}$, Ford Ballantyne IV ${ }^{1, a}$, Kyungjin Min ${ }^{1}$, and Sharon A. Billings ${ }^{1}$ \\ ${ }^{1}$ Department of Ecology and Evolutionary Biology, Kansas Biological Survey, University of Kansas, 2101 Constant Ave., \\ Lawrence, KS 66047, USA \\ anow at: Odum School of Ecology, University of Georgia, 140 E. Green St., Athens, GA 30602, USA
}

Correspondence to: Sharon A. Billings (sharon.billings@ku.edu)

Received: 11 September 2015 - Published in Biogeosciences Discuss.: 29 October 2015

Revised: 26 April 2016 - Accepted: 9 May 2016 - Published: 7 June 2016

\begin{abstract}
Understanding how carbon dioxide $\left(\mathrm{CO}_{2}\right)$ flux from ecosystems feeds back to climate warming depends in part on our ability to quantify the efficiency with which microorganisms convert organic carbon (C) into either biomass or $\mathrm{CO}_{2}$. Quantifying ecosystem-level respiratory $\mathrm{CO}_{2}$ losses often also requires assumptions about stable $\mathrm{C}$ isotope fractionations associated with the microbial transformation of organic substrates. However, the diversity of organic substrates' $\delta^{13} \mathrm{C}$ and the challenges of measuring microbial $\mathrm{C}$ use efficiency (CUE) in their natural environment fundamentally limit our ability to project ecosystem $\mathrm{C}$ budgets in a warming climate. Here, we quantify the effect of temperature on $\mathrm{C}$ fluxes during metabolic transformations of cellobiose, a common microbial substrate, by a cosmopolitan microorganism growing at a constant rate. Biomass $\mathrm{C}$ specific respiration rate increased by $250 \%$ between 13 and $26.5^{\circ} \mathrm{C}$, decreasing CUE from 77 to $56 \%$. Biomass $\mathrm{C}$ specific respiration rate was positively correlated with an increase in respiratory ${ }^{13} \mathrm{C}$ discrimination from 4.4 to $6.7 \%$ across the same temperature range. This first demonstration of a direct link between temperature, microbial CUE, and associated isotope fluxes provides a critical step towards understanding $\delta^{13} \mathrm{C}$ of respired $\mathrm{CO}_{2}$ at multiple scales, and towards a framework for predicting future ecosystem $\mathrm{C}$ fluxes.
\end{abstract}

\section{Introduction}

Because Earth's organic carbon (C) cycle is a key regulator of climate, a central goal of biogeochemistry is to understand biosphere-atmosphere $\mathrm{C}$ exchange. Globally, almost all C initially assimilated via photosynthesis is respired back to the atmosphere as $\mathrm{CO}_{2}$ by auto- and heterotrophic organisms (Schimel, 1995; Trumbore, 2006). Though we have a reasonably comprehensive understanding of how environmental conditions influence $\mathrm{CO}_{2}$ uptake by photosynthetic organisms, our understanding of how respiratory $\mathrm{CO}_{2}$ fluxes respond to environmental conditions significantly lags behind. This is especially true for respiratory $\mathrm{CO}_{2}$ derived from heterotrophs, which may account for more than half of respiratory $\mathrm{C}$ losses from soils and aquatic systems (Kucera and Kirkham, 1971; Hanson et al., 2000; Cotner and Biddanda, 2002; Subke et al., 2006). Metabolic rates of heterotrophs are expected to increase with rising temperatures (Gillooly et al., 2001; Pomeroy and Wiebe, 2001; Hall et al., 2008), which is of great concern given Earth's large reservoir of reduced organic matter (OM) that may be mineralized to $\mathrm{CO}_{2}$ via metabolism (Hedges et al., 2000; Kirschbaum, 2006). The influence of temperature on the physiology of heterotrophic microbes must therefore be well understood to project shifts in the global $\mathrm{C}$ balance in a warmer climate.

Existing knowledge of Earth's terrestrial $\mathrm{C}$ balance has been bolstered by the use of stable isotopes. A milestone for progress was when photosynthetic responses to environmental conditions were linked to differences between the stable $\mathrm{C}$ isotopic composition $\left(\delta^{13} \mathrm{C}\right)$ of atmospheric $\mathrm{CO}_{2}$ and that of plant products (Farquhar et al., 1982). These differences, caused by $\mathrm{C}$ isotope fractionation during $\mathrm{CO}_{2}$ diffu- 
sion into leaves and subsequent carboxylation (Park and Epstein, 1961; O'Leary, 1981), impart an isotopic fingerprint on ecosystem $\mathrm{C}$ pools and permit inference about $\mathrm{C}$ fluxes from $\delta^{13} \mathrm{C}$ of ecosystem $\mathrm{C}$ pools at multiple spatiotemporal scales (Farquhar and Richards, 1984; Pataki et al., 2003; Dijkstra et al., 2004; Barbosa et al., 2010). Recent studies remind us that respiratory $\mathrm{C}$ losses also leave an isotopic fingerprint on $\delta^{13} \mathrm{C}$ values of plant tissues via respiration of substrates with distinct $\delta^{13} \mathrm{C}$ (Bathellier et al., 2009; Brüggemann et al., 2011; Ghashghaie and Badeck, 2014), and via $C$ isotope fractionation during decarboxylation in respiratory pathways (Werner and Gessler, 2011; Werner et al., 2011; Tcherkez et al., 2012). Though not all C isotope fractionations during metabolism are well characterized, $\delta^{13} \mathrm{C}$ of metabolic reaction substrates and products can vary predictably, caused by kinetic or thermodynamic isotope effects (Rossmann et al., 1991; Gleixner and Schmidt, 1997; Cleland, 2005; Tcherkez et al., 2012). Accounting for isotope effects in plant respiratory $\mathrm{C}$ losses improves our ability to quantify the contributions of different pools to $\mathrm{CO}_{2}$ fluxes and thus our predictions of terrestrial ecosystem $\mathrm{C}$ budgets under changing environmental conditions. Using $\delta^{13} \mathrm{C}$ of heterotrophically respired $\mathrm{CO}_{2}$ holds similar promise, but if and how changing environmental conditions influence any fractionation factors for the fluxes associated with the liberation of $\mathrm{C}$ from $\mathrm{OM}$ is unknown.

Significant uncertainty about the direction and magnitude of $\mathrm{C}$ isotope fractionation during microbial $\mathrm{C}$ transformations (Bowling et al., 2008; Werth and Kuzyakov, 2010) renders quantifying microbial $\mathrm{CO}_{2}$ fluxes in ecosystems difficult. Difficulties arise because microbes in natural systems can access a diverse array of organic substrates with distinct $\delta^{13} \mathrm{C}$ signatures (Park and Epstein, 1961; Billings, 2006), the respiration of which influences $\delta^{13} \mathrm{C}$ of respired $\mathrm{CO}_{2}$. Though we know the growth rate of microbial populations influences $\mathrm{C}$ flux into and through biomass (Kayser et al., 2005), it is impossible to directly quantify microbial growth in situ. Furthermore, absence of steady-state conditions over a course of $\mathrm{CO}_{2}$ flux measurements makes the interpretation of temperature effects on the magnitude and the $\delta^{13} \mathrm{C}$ of ecosystem respiration an even greater challenge (Gamnitzer et al., 2011; Nickerson et al., 2013). Thus, establishing a mechanistic understanding of the links between temperature, microbial respiration rates, and $\mathrm{C}$ isotope fractionation during substrate transformations at a fundamental level requires that we characterize these processes as temperature changes in isolation from other factors that influence microbial C transformations.

To assess the influence of temperature on microbial growth and respiration rates, we grew a widely distributed gram-negative, heterotrophic bacterium (Pseudomonas $f u-$ orescens) in continuous culture bioreactors (chemostats) at 7 temperatures ranging from 13 to $26.5^{\circ} \mathrm{C}$ (Fig. 1) at reactor dilution rates of approximately $0.14 \mathrm{~h}^{-1}$, which is equivalent to the relative growth rates of the microbial popula-

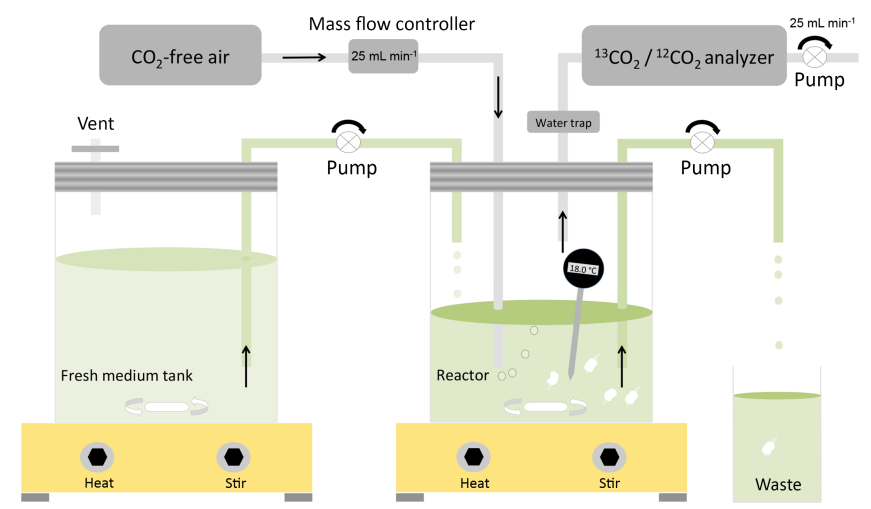

Figure 1. Chemostat system comprised of $P$. fluorescens growing on cellobiose. Seven independent experiments were conducted, with reactor temperatures of $13,14.5,16,18,21,23.5$, and $26.5^{\circ} \mathrm{C}$; all other conditions were identical. During continuous flow, dilution rate of the reactor $\left(\right.$ mean $=0.137 \pm 0.01 \mathrm{~h}^{-1}$ across all experiments) equals microbial growth rate. A peristaltic pump supplied fresh nutrient medium from a reservoir tank to the reactor and removed reactor medium (including biomass) at a constant rate. Headspace volume was flushed with $\mathrm{CO}_{2}$-free air, bubbling through reactor medium and supplying microorganisms with $\mathrm{O}_{2}$. A ${ }^{13} \mathrm{CO}_{2} /{ }^{12} \mathrm{CO}_{2}$ analyzer continuously sampled reactor headspace and measured the concentration and $\delta^{13} \mathrm{C}$ of respired $\mathrm{CO}_{2}$.

tions (Dawson, 1974; Smith and Waltman, 1995; Goldman and Dennett, 2000; Chrzanowski and Grover, 2008; Ferenci, 2008; Bull, 2010; Egli, 2015). We measured microbial respiration rates and $\delta^{13} \mathrm{C}$ of respired $\mathrm{CO}_{2}$ in this open, flowthrough system at steady state (Craig and Gordon, 1965; Fry, 2006; see the Supplement for a detailed elaboration of this approach). We computed the temperature dependence of a widely applied metric of microbial C use efficiency (CUE), defined as SGR/(SGR + SRR), where SGR and SRR are specific growth and specific respiration rates, respectively, with units of $\mathrm{C}$ per microbial biomass $\mathrm{C}$ and time. Our simplified system has several assets. First, it eliminates factors present in natural environments that preclude accurate assessment of specific growth and respiration rates, and thus accurate estimates of CUE as defined above. Second, obtaining accurate estimates of microbial CUE is critical for projecting $\mathrm{C}$ fluxes into the future because the particular value of CUE significantly influences $\mathrm{CO}_{2}$ loss rates from ecosystems in models of OM decomposition (Allison et al., 2010; Wieder et al., 2013). Finally, simultaneously quantifying differences in $\delta^{13} \mathrm{C}$ of organic substrate, microbial biomass $\mathrm{C}$ and respired $\mathrm{CO}_{2}$ along a temperature gradient is critical for partitioning synoptic $\mathrm{CO}_{2}$ measurements into component fluxes. 


\section{Materials and methods}

\subsection{Pre-cultivation of microorganisms for chemostat inoculation}

We pre-cultivated Pseudomonas fluorescens (Carolina Biological Supply, USA) in nutrient solution containing $10 \mathrm{mM}$ $\mathrm{NH}_{4} \mathrm{Cl}, 1.6 \mathrm{mM} \mathrm{KNO}_{3}, 2.6 \mathrm{mM} \mathrm{K}_{2} \mathrm{HPO}_{4}, 1.0 \mathrm{mM} \mathrm{KH}_{2} \mathrm{PO}_{4}$, $0.8 \mathrm{mM} \mathrm{MgSO}_{4}, 0.2 \mathrm{mM} \mathrm{CaCl}_{2}, 0.1 \mathrm{mM} \mathrm{CuCl}_{2}, 0.04 \mathrm{mM}$ $\mathrm{FeSO}_{4}, 0.03 \mathrm{mM} \mathrm{MnCl}$, and $0.02 \mathrm{mM} \mathrm{ZnSO}$, modified from Abraham et al. (1998). The sole $\mathrm{C}$ source in the nutrient medium was $10 \mathrm{mM}$ cellobiose $\left(\mathrm{C}_{12} \mathrm{H}_{22} \mathrm{O}_{11}\right.$; with a $\delta^{13} \mathrm{C}$ of $-24.2 \%$ ). Cellobiose is a disaccharide consisting of two glucose molecules and a basic module of cellulose. Thus, the $\mathrm{C}$ to $\mathrm{N}$ to $\mathrm{P}$ atomic ratio of the autoclaved, sterile nutrient solution was 100 to 10 to 3.3 ; its $\mathrm{pH}$ was adjusted to 6.5 . The bacteria grew for a few days in batch culture in a flask fitted with a vent for air exchange covered by a $0.22 \mu \mathrm{m}$ filter (Fisher Scientific, USA) to avoid contamination. Vessel contents were stirred continuously in an incubator maintained at $10^{\circ} \mathrm{C}$.

\subsection{The laboratory mesocosm - the chemostat}

The chemostat system was composed of two $1.9 \mathrm{~L}$ vessels, a medium reservoir tank and a reactor, each maintained on separate heating/stirring plates (Fig. 1) in separate incubators. The reactor volume was on average $870 \mathrm{~mL}$ (see the Supplement, Table S1). The reservoir tank was connected via a flexible tube to the reactor (Tygon E-LFL pump tubing, Masterflex, USA), which in turn had an outlet tube (Fig. 1; both tubes had a $1.6 \mathrm{~mm}$ inner diameter). When the chemostat was operated in "continuous culture mode" a peristaltic pump transported fresh medium to the reactor and simultaneously removed medium from the reactor at the same rate. Thus, reactor volume remained constant during all chemostat runs. The $0.22 \mu \mathrm{m}$ filter in the reservoir tank lid allowed for pressure compensation during withdrawal of nutrient solution in the continuous flow mode. Experimental temperatures were continuously measured with a thermometer (Oakton, USA) placed in the reactor medium (Fig. 1). This thermometer was routinely compared against an internal laboratory standard mercury thermometer, before and at the end of each experiment. The reactor temperatures were adjusted with heating/stirring plate and incubator settings, and kept constant during all experimental runs.

The reactor lid had two ports for gas lines. The outlet port tube was connected to a ${ }^{13} \mathrm{CO}_{2} /{ }^{12} \mathrm{CO}_{2}$ analyzer (G2101i, Picarro, USA) containing a pump that continuously removed air from the reactor headspace at an average rate of $0.025 \mathrm{~L} \mathrm{~min}^{-1}$. A water trap (magnesium perchlorate, Costech, USA) was installed between outlet port of the reactor and the gas analyzer. The $\mathrm{CO}_{2}$ analyzer recorded the concentration and the $\delta^{13} \mathrm{C}$ of the reactor headspace $\mathrm{CO}_{2}$ at $0.5 \mathrm{~Hz}$. The reactor's inlet tube was connected to a mass flow

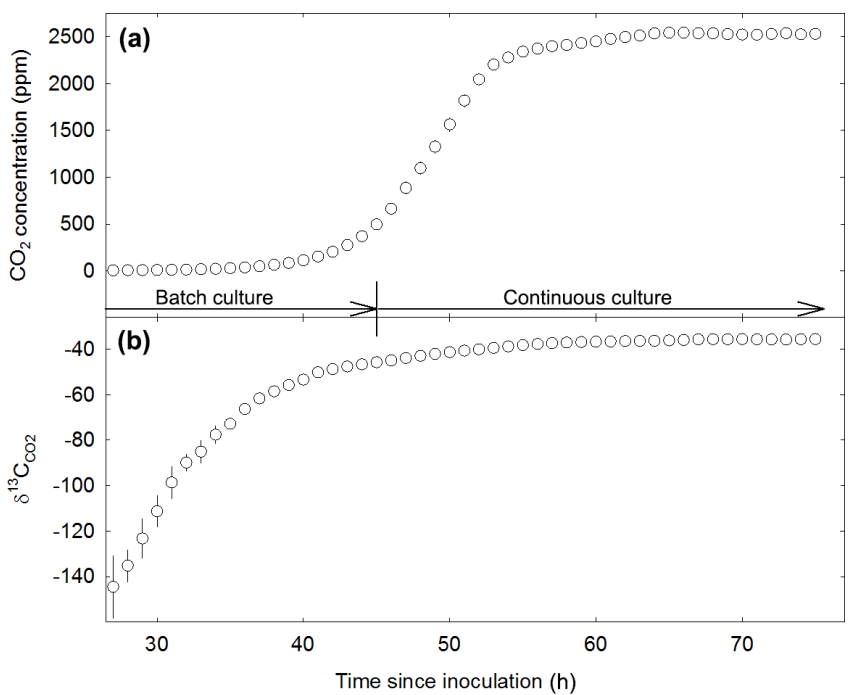

Figure 2. Example time course of the evolution of reactor headspace $\mathrm{CO}_{2}$ concentration (a) and $\delta^{13} \mathrm{C}$ of the $\mathrm{CO}_{2}$ (b) of the chemostat run at $23.5^{\circ} \mathrm{C}$ in hours since inoculation of the reactor with pre-cultured $P$. fluorescens. Data points are hourly means. Error bars (where visible) denote $\pm 1 \mathrm{SD}$. The reactor was shifted from batch to continuous culture mode $45 \mathrm{~h}$ after inoculation. Microbial respiration rate and the $\delta^{13} \mathrm{C}$ of respired $\mathrm{CO}_{2}$ were measured between 70 and $74 \mathrm{~h}$ after inoculation when the culture reached steady state.

controller (MC-50SCCM, Alicat Scientific, USA), which in turn, was connected to a gas cylinder containing $\mathrm{CO}_{2}$-free air (Fig. 1). The mass flow controller was programmed to maintain the reactor headspace at constant atmospheric pressure; thus, the $0.025 \mathrm{~L} \mathrm{~min}^{-1}$ headspace air removed by the ${ }^{13} \mathrm{CO}_{2} /{ }^{12} \mathrm{CO}_{2}$ analyzer pump was instantaneously replaced with $\mathrm{CO}_{2}$-free air flowing from the gas cylinder into the reactor medium. Assuming (1) that $1 \mathrm{~mol}$ of $\mathrm{O}_{2}$ is consumed per $1 \mathrm{~mol}$ of $\mathrm{CO}_{2}$ produced in aerobic respiration, (2) a typical reactor headspace $\mathrm{CO}_{2}$ concentration of around $2000 \mathrm{ppm}$ at steady state (see Fig. 2a and below), and (3) an $\mathrm{O}_{2}$ concentration of $21 \%$ in the air supply to the reactor, the air supply permitted continuous aerobic metabolism. Routine tests with $\mathrm{CO}_{2}$-free air in sterile chemostats were performed to ensure there were no leaks in the system.

\subsection{The chemostat run - standardized protocol and description of events}

We conducted seven independent chemostat runs, at temperatures of $13,14.5,16,18,21,23.5$, and $26.5^{\circ} \mathrm{C}$ at a dilution rate of, on average, $0.14 \mathrm{~h}^{-1}$, in random temporal order. For each of the chemostat runs, we inoculated the reactor with a $10 \mathrm{~mL}$ aliquot of the $P$. fluorescens pre-culture and activated the flow of $\mathrm{CO}_{2}$-free air through the reactor; this was considered time 0 . At the initial stage of a chemostat run, the bacteria grew in batch culture, that is, there was no flow of 
fresh nutrient medium from the reservoir tank to the reactor, and no removal of medium from the reactor (Fig. 1).

\subsubsection{Respiration measurements at chemical and isotopic equilibrium in the continuous flow chemostat at steady state}

At the initial $\mathrm{pH}$ of 6.5 , inorganic $\mathrm{C}$ in the fresh reactor medium was mainly in the form of $\mathrm{H}_{2} \mathrm{CO}_{3}$ (aq) and $\mathrm{HCO}_{3}^{-}$ (Stumm and Morgan, 1981). By continuously bubbling $\mathrm{CO}_{2}-$ free air into the reactor, we expelled these initial inorganic $\mathrm{C}$ pools from the reactor medium. This was evident by concentrations of reactor headspace $\mathrm{CO}_{2}$ of virtually zero in the early stages of batch culture after each run's inoculation (Fig. 2a). During the phase of rising reactor headspace $\mathrm{CO}_{2}$ via respiratory activity of the exponentially growing population (Fig. 2a), inorganic $\mathrm{C}$ in the reactor medium accrued with the increasing addition of $\mathrm{CO}_{2}$ from microbial respiration. That is, at any point in time during the phase of increasing reactor headspace $\mathrm{CO}_{2}$ concentration, the nutrient medium acted as a sink for respired $\mathrm{CO}_{2}$ (see also the Supplement).

Once the respiratory activity of the growing microbial population pushed the reactor headspace $\mathrm{CO}_{2}$ concentration above $500 \mathrm{ppm}$, we transferred the chemostat into the "continuous culture, open system" mode (Figs. 1, 2; Ferenci, 2008; Bull, 2010). The peristaltic pump henceforth transported fresh nutrient medium from the reservoir tank to the reactor at a constant rate of, on average, $118 \mathrm{~mL} \mathrm{~h}^{-1}$ (Table $\mathrm{S} 1$ ), and simultaneously removed medium from the reactor at the same rate so that the reactor volume remained constant. Initial chemostat experiments indicated that when headspace $\mathrm{CO}_{2}$ concentrations reached $500 \mathrm{ppm}$, the bacterial population was sufficiently dense to maintain itself without being washed out via dilution. Depending on the reactor temperature, the onset of the continuous culture mode occurred between $40 \mathrm{~h}\left(\right.$ at $26.5^{\circ} \mathrm{C}$ ) and $72 \mathrm{~h}$ (at $13^{\circ} \mathrm{C}$ ) after inoculation.

After the switch from batch to continuous culture, the rate of increase in reactor headspace $\mathrm{CO}_{2}$ concentration gradually slowed because cells were continuously diluted into the waste stream (Fig. 1), and approached a phase where the $\mathrm{CO}_{2}$ concentration became stable (Fig. 2a). At this point, bacteria grown in continuous culture had reached the phase of steadystate growth and physiology (see Ferenci, 2008; Bull, 2010). A key feature of the continuous culture chemostat relevant to our study is that at this steady state, the constant dilution rate of the reactor (the medium flow rate divided by the reactor volume) is equivalent to the specific growth rate of the microbial culture (Bull, 2010). That is, washout of cells with the nutrient medium flow is balanced by cell division so that the size of the population in the reactor can be expected to be reasonably constant in the time frames employed here (see discussion in Ferenci, 2008; Bull, 2010).
Critically, when reactor headspace $\mathrm{CO}_{2}$ concentrations approached the steady state, inorganic $\mathrm{C}$ pools came to their respective equilibria as well (Stumm and Morgan, 1981). At this point, pools of $\mathrm{H}_{2} \mathrm{CO}_{3}(\mathrm{aq})$ and $\mathrm{HCO}_{3}^{-}$were no longer a net sink for respired $\mathrm{CO}_{2}$. As reactor headspace $\mathrm{CO}_{2}$ concentrations reached steady state, the system supported constant microbial $\mathrm{CO}_{2}$ production reflective of steady-state growth under constant environmental conditions, and reflected chemical equilibrium (i.e., constant size) of the dissolved inorganic $\mathrm{C}$ pools. Thus, the rate of $\mathrm{CO}_{2}$ addition to the reactor headspace volume at steady state accurately represented the $\mathrm{CO}_{2}$ released during microbial respiration (see also the Supplement).

We calculated the molar $\mathrm{CO}_{2}$ production rate of the microbial population as the product of the average molar $\mathrm{CO}_{2}$ concentration measured by the ${ }^{13} \mathrm{CO}_{2} /{ }^{12} \mathrm{CO}_{2}$ analyzer for $5 \mathrm{~h}$ at steady state (Fig. 2a) multiplied by the molar air flow rate through the reactor, which was calculated as

air flow $\left.(\mathrm{mol} \mathrm{min})^{-1}\right)=0.96 \mathrm{~atm} \cdot 0.025 \mathrm{~L} \mathrm{~min}^{-1} /$

$$
\left(0.082 \mathrm{~atm} \mathrm{~L} \mathrm{~mol}^{-1} \mathrm{~K}^{-1} \cdot 296 \mathrm{~K}\right) \text {, }
$$

with $0.96 \mathrm{~atm}$ and $296 \mathrm{~K}$ being the barometric pressure and the temperature in the lab where the experiments were performed, $0.025 \mathrm{~L} \mathrm{~min}^{-1}$ the average volumetric headspace flow rate through the reactor and $0.082 \mathrm{~atm} \mathrm{~L} \mathrm{~mol}^{-1} \mathrm{~K}^{-1}$ the gas constant.

The $\delta^{13} \mathrm{C}$ of the reactor headspace $\mathrm{CO}_{2}$ during the earliest batch culture phase was generally very negative; the ${ }^{13} \mathrm{CO}_{2} /{ }^{12} \mathrm{CO}_{2}$ analyzer cannot accurately measure ${ }^{13} \mathrm{C}$ and ${ }^{12} \mathrm{C}$ in very low $\mathrm{CO}_{2}$ concentrations (Fig. 2b). The $\delta^{13} \mathrm{C}$ of reactor headspace $\mathrm{CO}_{2}$ became less negative as the $\mathrm{CO}_{2}$ concentration increased (Fig. 2b). During the "climbing" phase of the reactor headspace $\mathrm{CO}_{2}$, the $\delta^{13} \mathrm{C}$ of the $\mathrm{CO}_{2}$ pool was influenced by isotopic fractionation among gaseous $\mathrm{CO}_{2}$, $\mathrm{H}_{2} \mathrm{CO}_{3}$ (aq) and $\mathrm{HCO}_{3}^{-}$(Vogel et al., 1970; Mook et al., 1974; Stumm and Morgan, 1981; Szaran, 1997), because the dissolved inorganic $\mathrm{C}$ pools functioned as a net sink for respired $\mathrm{CO}_{2}$. At steady state, with constant headspace $\mathrm{CO}_{2}$ concentrations and constant size of the dissolved inorganic $\mathrm{C}$ pools (see above), isotopic equilibrium was achieved, evidenced by constant $\delta^{13} \mathrm{C}$ readings of reactor headspace $\mathrm{CO}_{2}$ (Fig. 2b). As such, in this open system at steady state, the $\delta^{13} \mathrm{C}$ of the $\mathrm{CO}_{2}$ leaving the reactor (the $\mathrm{CO}_{2}$ measured by the analyzer) is identical to the $\delta^{13} \mathrm{C}$ of microbial respiration (Craig and Gordon, 1965; Fry, 2006). Importantly, this principle is valid irrespective of temperature, microbial growth rate, or microbial biomass in the reactor. (See the Supplement for an elaboration of the principle of chemical and isotopic equilibrium.)

We used the average $\delta^{13} \mathrm{C}$ measurement of reactor headspace $\mathrm{CO}_{2}$ over the same $5 \mathrm{~h}$ in the stable phase employed for calculations of microbial respiration rates (see above) as the isotopic signature of $\mathrm{CO}_{2}$ respired by the microbial culture at each temperature. Any measurements of 
headspace $\mathrm{CO}_{2}$ and $\delta^{13} \mathrm{C}$ during the climbing phase before steady state (Fig. 2) were not used in these calculations.

For the example chemostat at $23.5^{\circ} \mathrm{C}$, the half-life of the reactor $\left(t_{1 / 2}\right)$, i.e., the time it took until $50 \%$ of the reactor medium was exchanged with fresh tank medium, was $5.2 \mathrm{~h}$ (with $t_{1 / 2}=\ln (2) /($ medium flow rate/reactor volume); Table S1). In a homogeneous, well-mixed system such as that employed here, $95 \%$ of the pool (i.e., the reactor) is exchanged with new medium within approximately 5 times the half-life. Thus, during the respiration measurements between time 70 and $74 \mathrm{~h}$ (in the example time course in Fig. 2), any "leftovers" from the batch culture mode were insignificant, and the microbial culture could be considered homogeneous. This principle was applicable to all chemostat runs we performed.

After the $5 \mathrm{~h}$ respiration measurements were completed, we disconnected the gas lines from the reactor, connected the mass flow controller directly to the ${ }^{13} \mathrm{CO}_{2} /{ }^{12} \mathrm{CO}_{2}$ analyzer, and replaced the $\mathrm{CO}_{2}$-free air cylinder with a reference gas cylinder containing $1015 \mathrm{ppm} \mathrm{CO} 2$ at a $\delta^{13} \mathrm{C}$ of $-48.9 \%$ o (Matheson, USA). This laboratory standard gas was previously calibrated against secondary $\mathrm{CO}_{2}$ standards $($ Oztech, USA) and served for any necessary corrections of the $\delta^{13} \mathrm{C}$ of the reactor headspace $\mathrm{CO}_{2}$ measurements. Across the seven standard measurement procedures after each individual chemostat run, the $\delta^{13} \mathrm{C}$ measured for the laboratory standard gas showed only slight variation $\left(1 \mathrm{SD}=0.16 \%\right.$ ). $\mathrm{CO}_{2}$ concentration measurements needed no correction; measurements of lab-internal gases with previously determined $\mathrm{CO}_{2}$ concentrations between chemostat runs showed very stable and accurate analyzer performance.

\subsubsection{Measurements of extracellular enzyme activities at steady state}

Using principles detailed by Lehmeier et al. (2013) and Min et al. (2014), we tested reactor medium for activity of the extracellular enzymes $\beta$-glucosidase and $\beta$ - $\mathrm{N}$-acetyl glucosaminidase across all chemostat temperatures; we never detected extracellular activity of either enzyme. The lack of extracellular $\beta$-glucosidase activity indicates that the sole $\mathrm{C}$ source, cellobiose, was directly taken up by microbes and cleaved intracellularly into glucose monomers for further metabolism. The lack of extracellular $\beta$-N-acetyl glucosaminidase activity suggests that the inorganic $\mathrm{N}$ provided in nutrient medium was the sole source of $\mathrm{N}$ taken up by $P$. fluorescens. These findings do not rule out the possibility that P. fluorescens may have taken up (i.e., recycled) any exuded $\mathrm{C}$-based metabolic compounds, although such a scenario in continuous culture conditions may not appear to be energetically favorable. Thus, the assumption that the sole resources used by $P$. fluorescens were the cellobiose and the nutrient medium appears reasonable.

\subsubsection{Harvest of microbial biomass at steady state}

Immediately after completing the $5 \mathrm{~h}$ respiration measurements, we filtered approximately $300 \mathrm{~mL}$ of reactor medium for steady-state microbial biomass using $0.2 \mu \mathrm{m}$ filters made of polyethersulfone (Pall, USA) and a vacuum pump. The filters had previously been oven dried for $48 \mathrm{~h}$ at $75^{\circ} \mathrm{C}$ and their dry weight determined. We then oven dried the filters post filtration for $48 \mathrm{~h}$ at $75^{\circ} \mathrm{C}$, removed some of the dry biomass and weighed $1.2 \mathrm{mg}$ of the material into tin cups for subsequent combustion in an elemental analyzer (1110 CHN Combustion Analyzer, Carlo Erba Strumentazione, Italy) coupled to a ThermoFinnigan DeltaPlus mass spectrometer (Finnigan MAT, Germany) at the Keck Paleoenvironmental and Environmental Stable Isotope Laboratory (The University of Kansas, USA). We thus determined biomass C (and N) elemental content, as well as the $\delta^{13} \mathrm{C}$ of the biomass. In this analysis, the samples were compared against a laboratory standard $\mathrm{CO}_{2}$ previously calibrated against the same secondary $\mathrm{CO}_{2}$ standards as used in calibration of the $\mathrm{CO}_{2}$ standard used for respiration measurements (see above). The $\delta^{13} \mathrm{C}$ of the substrate cellobiose was measured likewise. Dry weight of the sampled reactor aliquots and the C content obtained from elemental analysis served to calculate total microbial $\mathrm{C}$ content in the steady-state reactor and to calculate specific respiration rates.

At all temperatures studied, biomass $\mathrm{C}$ and $\mathrm{N}$ contents were virtually the same, on average 27 and $8 \%$ of microbial dry mass, respectively (Table S1). From mass balance calculations, we determined that only a small percentage of the $\mathrm{C}$ and $\mathrm{N}$ supplied via fresh medium from the tank was taken up to fuel microbial growth (2.8 and $4.3 \%$ on average for C and $\mathrm{N}$, respectively). This suggests that the observed temperature effects on specific respiration rates and CUE were not confounded by any differences in $\mathrm{C}$ and $\mathrm{N}$ limitations at the different temperatures (Goldman and Dennet, 2000; Cotner et al., 2006; Chrzanowski and Grover, 2008).

\section{Results and Discussion}

For $P$. fluorescens grown in continuous culture, CUE, defined as $\mathrm{SGR} /(\mathrm{SGR}+\mathrm{SRR})$, declined with increasing temperature, from $77 \%$ at $13{ }^{\circ} \mathrm{C}$ to $56 \%$ at $26.5^{\circ} \mathrm{C}$ (Fig. 3a). Because specific growth rates were similar across the experimental temperatures $\left(137 \mathrm{mg} \mathrm{g}^{-1} \mathrm{~h}^{-1}, \pm 8(1 \mathrm{SD})\right.$; or $13.7 \% \mathrm{~h}^{-1}$ in relative terms; Fig. 3b), the decline in CUE was due to the 2.5-fold increase of SRR with temperature, which rose from $45 \mathrm{mg} \mathrm{g}^{-1} \mathrm{~h}^{-1}$ at $13^{\circ} \mathrm{C}$ to $113 \mathrm{mg} \mathrm{g}^{-1} \mathrm{~h}^{-1}$ at $26.5^{\circ} \mathrm{C}$ (Fig. 3b). The decline in CUE is also evident in the more than $50 \%$ reduction in steady-state dry microbial biomass with increasing temperature (Fig. 3a). For example, though SGR was approximately the same and thus the fraction of biomass replaced per time similar across all experimental temperatures $\left(0.147\right.$ and 0.141 at $13^{\circ} \mathrm{C}$ and $26.5^{\circ} \mathrm{C}$, respectively; 
Fig. 3b), microbes at $13{ }^{\circ} \mathrm{C}$ generated $20.9 \mathrm{mg}$ biomass $\mathrm{h}^{-1}$ while those at $26.5^{\circ} \mathrm{C}$ generated less than half the amount

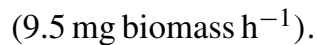

Because we did not quantify possible $\mathrm{C}$ losses from the population at steady state such as secretion of organic acids or other compounds (El-Mansi and Holms, 1989; Nanchen et al., 2006), gross rates of steady-state cellobiose $\mathrm{C}$ uptake may have been slightly higher than what was calculated from the sum of SGR and SRR. However, the direct observation of P. fluorescens' CUE is consistent with the negative effect of increasing temperature on microbial CUE widely reported in literature for soils and aquatic ecosystems (del Giorgio and Cole, 1998; Gillooly et al., 2001; Rivkin and Legendre, 2001; Apple et al., 2006; Manzoni et al., 2012; Frey et al., 2013; Tucker et al., 2013).

Across the chemostat runs, we observed strong $\mathrm{C}$ isotope fractionations, which created pronounced differences in $\delta^{13} \mathrm{C}$ between microbial biomass and the sole $\mathrm{C}$ substrate, cellobiose, and between microbial biomass and respired $\mathrm{CO}_{2}$ (Fig. 4). Microbial biomass exhibited 5.5-10.5\%o more negative $\delta^{13} \mathrm{C}$ values than the cellobiose and respired $\mathrm{CO}_{2}$ was even more ${ }^{13} \mathrm{C}$ depleted, at least $4.4 \%$ more negative than the biomass (Fig. 4a). Because each chemostat was at steady state, isotopic mass balance dictates that ${ }^{13} \mathrm{C}$ "missing" from cellobiose had to accumulate in another pool in the reactor. The only pool that could have been enriched with the "missing" ${ }^{13} \mathrm{C}$ was reactor $\mathrm{DOC}$, which we analyzed for $\delta^{13} \mathrm{C}$ in four out of the seven chemostat runs (Fig. 4a). Reactor DOC consisted of a large pool of cellobiose (because the rate of $\mathrm{C}$ consumption by the chemostat cultures was, on average, only $2.8 \%$ of the rate of C supply) and presumably a pool of additional organic compounds (e.g., acetate). Such compounds appear to be typically secreted from microbial cells at low rates in aerobic chemostats operated at dilution rates similar to those of our runs (El-Mansi and Holms, 1989; Nanchen et al., 2006), and have been shown to be enriched in ${ }^{13} \mathrm{C}$ compared to cellular biomass (Blair et al., 1985). However, because such a small fraction of the available cellobiose was taken up by $P$. fluorescens, the fraction of total DOC comprised of secreted organic compounds was small. As a result, ${ }^{13} \mathrm{C}$ enrichment of any microbial exudates was insufficient to enrich bulk DOC to an extent detectable by the isotope ratio mass spectrometer (Fig. 4a).

The majority of the fractionation between $P$. fluorescens biomass and the substrate was most likely due to discrimination against ${ }^{13} \mathrm{C}$ during cellobiose uptake. If we assume that $P$. fluorescens secreted organic compounds at a rate of $10 \%$ of the sum of SGR and SRR (El-Mansi and Holms, 1989 ) and that the bacteria did not discriminate against ${ }^{13} \mathrm{C}$ containing cellobiose during uptake (and thus assimilated cellobiose possessed a $\delta^{13} \mathrm{C}$ of $-24.2 \%$ ), isotopic mass balance dictates that the $\delta^{13} \mathrm{C}$ of the $\mathrm{C}$ secretion flux (Fig. 5) would have to be $+70 \%$, at minimum, across all temperatures. To our knowledge, such high metabolic discrimination against ${ }^{13} \mathrm{C}$ would be very unusual for biological systems
(O'Leary, 1981). An alternative and more likely scenario is therefore that $P$. fluorescens took up less ${ }^{13} \mathrm{C}$-containing cellobiose than was supplied as substrate, and that discrimination during uptake contributed substantially to $P$. fluorescens biomass and respired $\mathrm{CO}_{2}$ being more ${ }^{13} \mathrm{C}$ depleted than the cellobiose supplied. This conclusion holds for all temperatures studied. If we assume for the example $23.5^{\circ} \mathrm{C}$ chemostat run at steady state (Figs. 2, 5) that P. fluorescens secreted organic compounds at a rate of $10 \%$ of the sum of SGR and $\mathrm{SRR}$, and we further assume that the $\delta^{13} \mathrm{C}$ of secreted compounds was $11.7 \%$ o less negative than that of the biomass (Blair et al., 1985), that is $-18.1 \%$, then the $\delta^{13} \mathrm{C}$ of the cellobiose taken up would have been $-31.1 \%$, which is only a $7 \%$ difference from the cellobiose provided, and therefore probably a more likely scenario (Fig. 5).

Substantial ${ }^{13} \mathrm{C}$ depletion of respired $\mathrm{CO}_{2}$ relative to microbial biomass has not, to our knowledge, been reported in other studies. With the microbial $\mathrm{C}$ consumption rate amounting to only $2.8 \%$ of the rate of $\mathrm{C}$ supply, $\mathrm{C}$ availability was high compared to what microbes in their natural environments typically experience (Tempest and Neijssel, 1978; Cole et al., 1988; Hobbie and Hobbie, 2013), potentially promoting enzymatic discrimination. The cellobiose $\delta^{13} \mathrm{C}$ of $-24.2 \%$ implies a ${ }^{13} \mathrm{C} /{ }^{12} \mathrm{C}$ ratio of $\sim 1 / 91$. Considering the molecular formula of cellobiose $\mathrm{C}_{12} \mathrm{H}_{22} \mathrm{O}_{11}$, this means that not more than about one out of eight cellobiose molecules in the supplied substrate included a ${ }^{13} \mathrm{C}$ atom. Faster diffusion of the isotopically lighter cellobiose molecules may have contributed to a lower probability of ${ }^{13} \mathrm{C}$-containing cellobiose approaching bacterial membrane uptake sites, and hence, to the differences between $\delta^{13} \mathrm{C}$ of substrate and biomass (Fig. 4a). However, isotope fractionation during diffusion - a physical process dependent on compound mass - would likely exhibit a continuous temperature response. Thus, it seems unlikely that fractionation during diffusion was the primary driver of the pronounced, discontinuous changes in the difference between substrate and biomass $\delta^{13} \mathrm{C}$, which ranged from 5.5 to $10.5 \%$ (Fig. 4a). Rather, this variation, with one apparently linear part between 13 and $16^{\circ} \mathrm{C}$ and another between 18 and $23.5^{\circ} \mathrm{C}$, may be explained parsimoniously by a significant, discontinuous reorganization of enzyme-mediated $\mathrm{C}$ fluxes into and out of bacterial cells (see Nanchen et al., 2006), induced by differences in temperature at which P. fluorescens was growing and the related differences in substrate uptake rates.

Evidence from work on $\mathrm{C}$ isotope distribution within carbohydrate molecules (e.g., Rossmann et al., 1991; Gleixner and Schmidt, 1997) suggests non-random distribution of ${ }^{13} \mathrm{C}$ in biological molecules (such as cellobiose). Based on such phenomena, it is probable that the ${ }^{13} \mathrm{C}$ atom in ${ }^{13} \mathrm{C}$ containing cellobiose was consistently at the same position within the molecule, which rules out the possibility that any changes in the intramolecular ${ }^{13} \mathrm{C}$ distribution of cellobiose were responsible for the observed $\delta^{13} \mathrm{C}$ patterns in biomass and respired $\mathrm{CO}_{2}$ (Fig. 4). Hence, the discontinuous pattern 

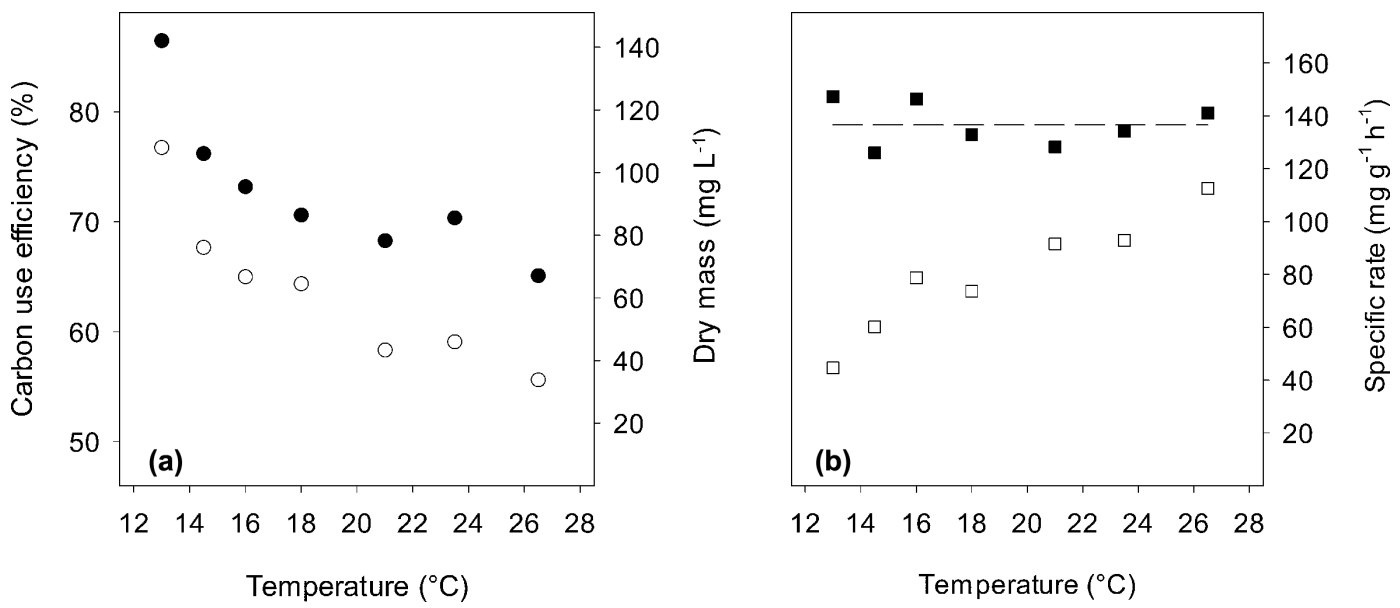

Figure 3. Steady-state process variables of $P$. fluorescens growing in chemostats at specified temperatures. Microbial carbon use efficiency $(\circ ; \mathbf{a})$, dry microbial biomass $(\bullet ; \mathbf{a})$; specific growth rate $(\mathbf{\square} ; \mathbf{b})$; and specific respiration rate $(\circ$; b), expressed in milligrams of $\mathrm{C}$ per gram of microbial biomass $\mathrm{C}$ and hour. The dashed line denotes the average of the seven specific growth rates $\left(137 \mathrm{mg} \mathrm{g}^{-1} \mathrm{~h}^{-1}\right)$.
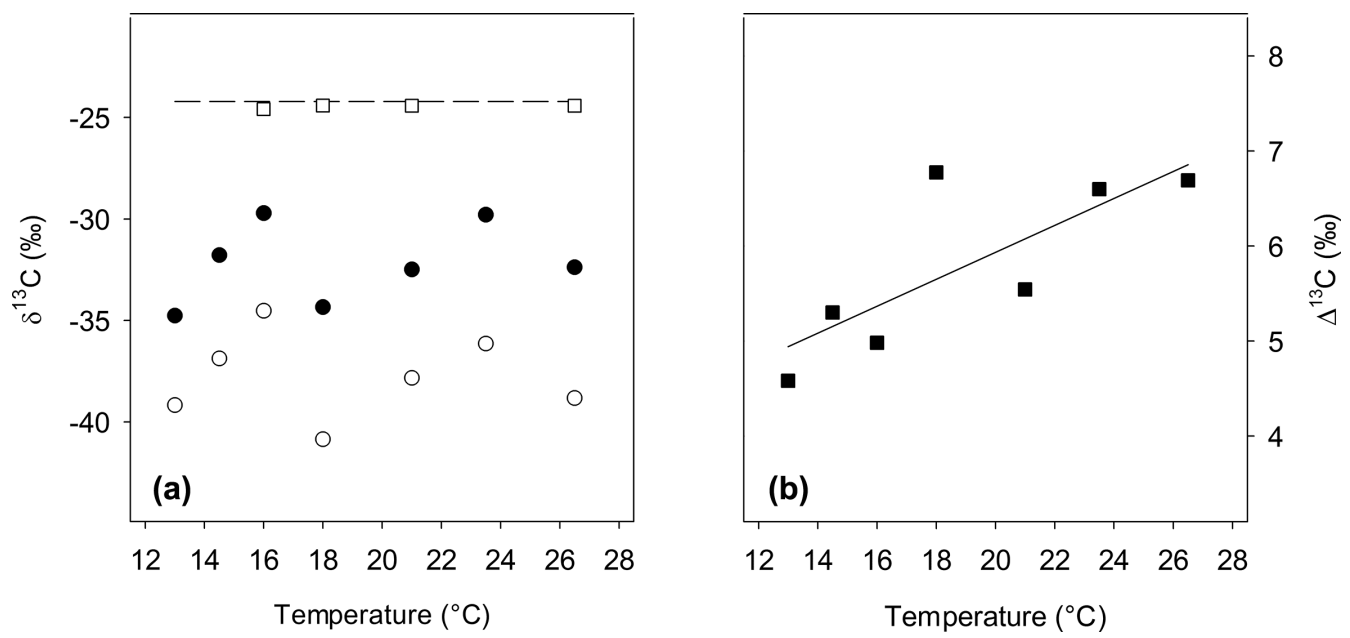

Figure 4. Steady-state $\delta^{13} \mathrm{C}$ of microbial biomass $(\bullet ; \mathbf{a})$ and respired $\mathrm{CO}_{2}(\circ ; \mathbf{a})$, and $\mathrm{C}$ isotope discrimination during respiration $\left(\Delta^{13} \mathrm{C}\right.$; b) of $P$. fluorescens growing in chemostats at specified temperatures. In panel a, the dashed line denotes the $\delta^{13} \mathrm{C}$ of the substrate cellobiose $(-24.2 \%)$, and $\delta^{13} \mathrm{C}$ of reactor filtrate is shown as open squares; standard errors, derived from multiple measurements across time during

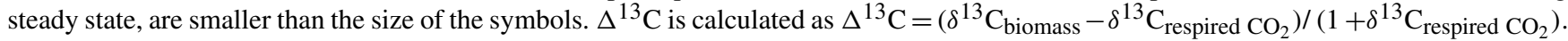
The solid line denotes linear regression of $\Delta^{13} \mathrm{C}$ vs. temperature $\left(\mathrm{y}=0.14 \times+3.1 ; R^{2}=0.61 ; P=0.04\right)$.

of $\delta^{13} \mathrm{C}$ of respired $\mathrm{CO}_{2}$ with temperature, similar to the pattern for $\delta^{13} \mathrm{C}$ of the biomass (Fig. 4a), presumably reflects the downstream consequence of an upstream change in $\delta^{13} \mathrm{C}$ of the metabolic substrate taken up and ultimately respired. However, the more negative $\delta^{13} \mathrm{C}$ of respired $\mathrm{CO}_{2}$ compared to that of biomass is, to our knowledge, the most direct evidence to date for ${ }^{13} \mathrm{C}$ discrimination during respiration of a heterotrophic microbe. The observation of a substantial respiratory ${ }^{13} \mathrm{C}$ discrimination corroborates inferences drawn in earlier studies (Ŝantrůčková et al., 2000; Fernandez and Cadisch, 2003) and is also consistent with plant studies reporting $\mathrm{C}$ isotope discrimination during dark respiration in roots (Klumpp et al., 2005; Bathellier et al., 2009;
Ghashghaie and Badeck, 2014). Our observations of respiratory discrimination against ${ }^{13} \mathrm{C}$ highlight the similarity of heterotrophic, aerobic respiratory pathways, and isotope effects within them, across life's domains.

In contrast to the discontinuous relationship between biomass $\delta^{13} \mathrm{C}$ and temperature, we observed a comparably continuous and linear increase in respiratory discrimination against ${ }^{13} \mathrm{C}$ with temperature (Fig. $4 \mathrm{~b}$ ). This increase generated a marginally positive significant $(P=0.08)$ correlation with SRR (Fig. 6), and hence a marginally significant $(P=0.07)$ correlation with CUE. A physiological interpretation of this finding is not straightforward, as multiple, possibly simultaneous enzymatic fractionations may have con- 


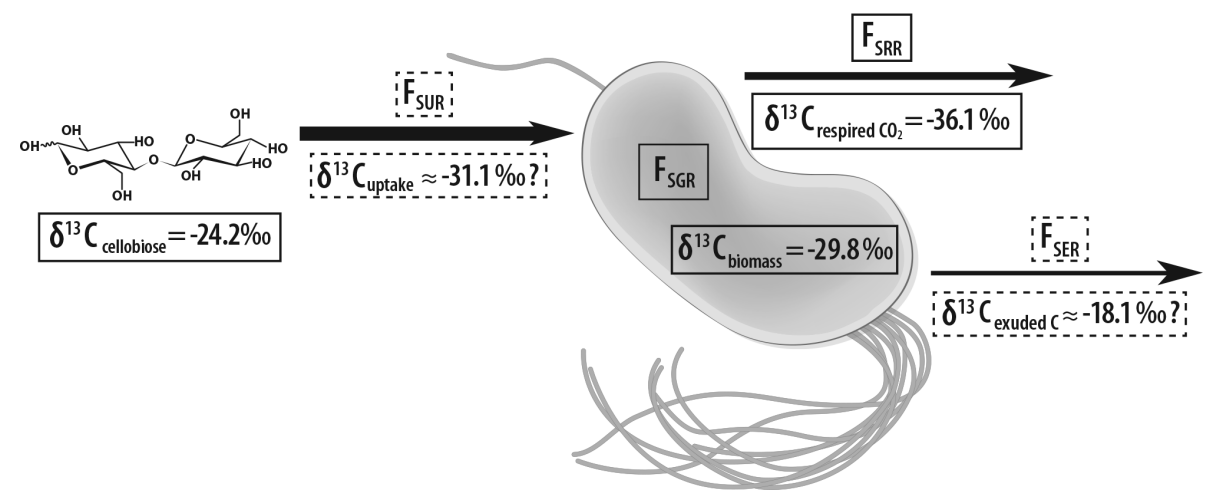

Figure 5. Schematic of an individual $P$. fluorescens cell, representing the sample population growing at $23.5^{\circ} \mathrm{C}$ with one available substrate at a constant relative growth rate of $0.14 \mathrm{~h}^{-1}$ at steady state (Fig. 2), with measured (solid boxes) and estimated (dashed boxes) magnitudes of $\mathrm{C}$ and ${ }^{13} \mathrm{C}$ fluxes into and out of the population. Designated fluxes include specific uptake rate of cellobiose $\left(F_{\mathrm{SUR}}\right)$, specific growth rate $\left(F_{\mathrm{SGR}}\right)$, specific respiration rate $\left(F_{\mathrm{SRR}}\right)$, and specific excretion rate $\left(F_{\mathrm{SER}}\right)$, in relation to steady-state biomass $\mathrm{C}$ in the chemostat, where $F_{\mathrm{SUR}}=F_{\mathrm{SGR}}+F_{\mathrm{SRR}}+F_{\mathrm{SER}}$. The estimate of $\delta^{13} \mathrm{C}_{\text {uptake }}$ is based on the assumption that $\delta^{13} \mathrm{C}_{\text {exuded } \mathrm{C}}$ is $11.7 \%$ less negative than $\delta^{13} C_{\text {biomass }}$ (Blair et al., 1985) and that $F_{\text {SER }}$ is $10 \%$ of the sum of $F_{\text {SGR }}$ and $F_{\text {SRR }}$ (El-Mansi and Holms, 1989). In contrast to this experimental system, in natural environments measurements of boxed pools and fluxes can be confounded by the presence of dormant microorganisms, unknown microbial growth rates, diverse available substrates, and a lack of steady-state $\mathrm{CO}_{2}$ fluxes.

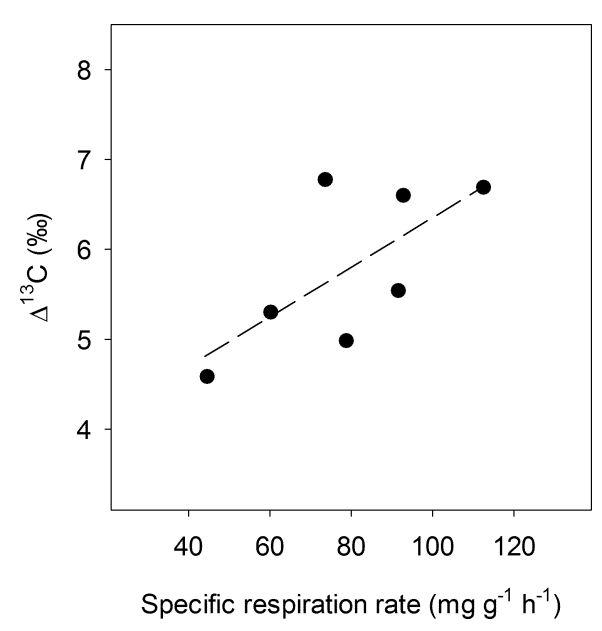

Figure 6. Correlation between the specific respiration rate (in $\mathrm{mg} \mathrm{C}$ per g microbial biomass $\mathrm{C}$ and hour) of $P$. fluorescens growing in continuous chemostat culture at temperatures ranging from 13 to $26.5^{\circ} \mathrm{C}$ and the carbon isotope discrimination during respiration. The dashed line denotes a linear regression of the form $y=0.03 \times+3.6 ; R^{2}=0.48 ; P=0.08$.

tributed to the observed $\delta^{13} \mathrm{C}$ of respired $\mathrm{CO}_{2}$ (Dijkstra et al., 2011; Tcherkez et al., 2012). It could simply result from a proportionally increasing flux through respiratory pathways, with associated stronger expression of ${ }^{13} \mathrm{C}$ discrimination by the enzymes involved (Tcherkez et al., 2012), or could result from increasing temperatures altering the relative fluxes through respiratory pathways (Chung et al., 1976; Wittmann et al., 2007; Dijkstra et al., 2011) such that the overall observed respiratory ${ }^{13} \mathrm{C}$ discrimination increased with temperature. This may be possible given that respiratory pathways can exhibit distinct fractionation factors (Bathellier et al., 2009 and references therein) and prompt different, specific C atoms to undergo decarboxylation from the two glucose units of the substrate cellobiose, which contain non-randomly distributed ${ }^{13} \mathrm{C}$ atoms (Rossmann et al., 1991; Gleixner and Schmidt, 1997). If relative fluxes through different respiratory pathways changed with temperature, the continuous nature of the relationship between temperature and respiratory ${ }^{13} \mathrm{C}$ discrimination suggests a smooth transition compared to the abrupt and discontinuous shifts in apparent uptake and/or secretion discrimination described above. Future metabolic flux analyses linked to isotopic approaches sensitive enough to quantify $\mathrm{C}$ isotopes in microbial exudation will be well suited to explore how $\mathrm{C}$ allocation to distinct, aerobic respiratory pathways may vary with temperature and result in varying $\delta^{13} \mathrm{C}$ of respired $\mathrm{CO}_{2}$.

\section{Conclusions}

Our observations clearly show a decline in microbial CUE with increasing temperature when $\mathrm{C}$ substrate is plentiful and demonstrate the mechanism driving it - an increase in SRR. The relationship between CUE and temperature underscores the importance of incorporating variable, temperature dependent SRR, which influences CUE and growth efficiency, in ecosystem process models. The temperature-driven changes in SRR and respiratory discrimination against ${ }^{13} \mathrm{C}$ were not independent of each other, suggesting that increasing SRR, to some degree, drives enhanced $\mathrm{C}$ isotopic discrimination. We demonstrate that $\mathrm{C}$ isotope discrimination associated with microbial decomposition of OM can impart large and variable isotopic signatures on $\mathrm{C}$ pools typically characterized 
and interpreted in biogeochemical studies at any scale. Further exploration of the drivers of $\mathrm{C}$ isotope fractionations during microbial OM transformations could exploit an experimental approach similar to that presented here to investigate the roles of resource stoichiometry, identity of the organism or the supplied substrate, or competition among microbial populations. To date, efforts to partition flux components of net ecosystem exchange have assumed little to no fractionation between respired substrates and the resultant $\mathrm{CO}_{2}$. Our results suggest that this assumption must be reevaluated, and represent a first step towards an isotopically explicit, mechanistic framework for microbial C isotope fluxes in Earth system models.

\section{Data availability}

The data presented in this study are available for collaborative use by anyone interested; contact the corresponding author for access to the data.

\section{The Supplement related to this article is available online at doi:10.5194/bg-13-3319-2016-supplement.}

Author contributions. Christoph A. Lehmeier and Kyungjin Min performed the experiments; all authors contributed to all other parts and stages of the manuscript.

Acknowledgements. We thank Susan Ziegler, Jarad Mellard, and Chao Song for helpful discussions during the design of the experiments; Greg Caine for expert stable isotope analysis and the provision of isotopic standards, Susan Ziegler, Mike Burrell, Karl Auerswald, Hanns-Ludwig Schmidt and John Kelly for comments on the manuscript; Gil Ortiz with assistance generating Fig. 5; the anonymous referees for their time and constructive comments; and the National Science Foundation of the USA for funding (grant no. DEB-0950095 and EAR-1331846).

Edited by: E. Pendall

\section{References}

Abraham, W.-R., Hesse, C., and Pelz, O.: Ratios of carbon isotopes in microbial lipids as an indicator of substrate usage, Appl. Environ. Microb., 64, 4202-4209, 1998.

Allison, S. D., Wallenstein, M. D., and Bradford, M. A.: Soil-carbon response to warming dependent on microbial physiology, Nat. Geosci., 3, 336-340, 2010.

Apple, J. K., del Giorgio, P. A., and Kemp, W. M.: Temperature regulation of bacterial production, respiration, and growth efficiency in a temperate salt-marsh estuary, Aquat. Microb. Ecol., 43, 243-254, 2006.
Barbosa, Î. C. R., Köhler, I. H., Auerswald, K., Lüps, P., and Schnyder, H.: Last-century changes of alpine grassland water-use efficiency: a reconstruction through carbon isotope analysis of a time -series of Capra ibex horns, Glob. Change Biol., 16, 1171-1180, 2010.

Bathellier, C., Tcherkez, G., Bligny, R., Gout, E., Cornic, G., and Ghashghaie, J.: Metabolic origin of the $\delta^{13} \mathrm{C}$ of respired $\mathrm{CO}_{2}$ in roots of Phaseolus vulgaris, New Phytol., 181, 387-399, 2009.

Billings, S.: Soil organic matter dynamics and land use change at a grassland/forest ecotone, Soil Biol. Biochem., 38, 2934-2943, 2006.

Blair, N., Leu, A., Muñoz, E., Olsen, J., Kwong, E., and Des Marais, D.: Carbon isotopic fractionation in heterotrophic microbial metabolism, Appl. Environ. Microb., 50, 996-1001, 1985.

Bowling, D. R., Pataki, D. E., and Randerson, J. T.: Carbon isotopes in terrestrial ecosystem pools and $\mathrm{CO}_{2}$ fluxes, New Phytol., 178, 24-40, 2008.

Brüggemann, N., Gessler, A., Kayler, Z., Keel, S. G., Badeck, F., Barthel, M., Boeckx, P., Buchmann, N., Brugnoli, E., Esperschütz, J., Gavrichkova, O., Ghashghaie, J., Gomez-Casanovas, N., Keitel, C., Knohl, A., Kuptz, D., Palacio, S., Salmon, Y., Uchida, Y., and Bahn, M.: Carbon allocation and carbon isotope fluxes in the plant-soil-atmosphere continuum: a review, Biogeosciences, 8, 3457-3489, doi:10.5194/bg-8-3457-2011, 2011.

Bull, A. T.: The renaissance of continuous culture in the postgenomics age, J. Ind. Microbiol. Biot., 37, 993-1021, 2010.

Chrzanowski, T. H. and Grover, J. P.: Element content of Pseudomonas fluorescens varies with growth rate and temperature: A replicated chemostat study addressing ecological stoichiometry, Limnol. Oceanogr., 53, 1242-1251, 2008.

Chung, B. H., Cannon, R. Y., and Smith, R. C.: Influence of growth temperature on glucose metabolism of a psychrotrophic strain of Bacillus cereus, Appl. Environ. Microb., 31, 39-45, 1976.

Cleland, W. W.: The use of isotope effects to determine enzyme mechanisms, Arch. Biochem. Biophys., 433, 2-12, 2005.

Cole, J. J., Findlay, S., and Pace, M. L.: Bacterial production in fresh and saltwater ecosystems: a cross-system overview, Mar. Ecol.-Prog. Ser., 43, 1-10, 1988.

Cotner, J. B. and Biddanda, B. A.: Small players, large role: microbial influence on biogeochemical processes in pelagic aquatic ecosystems, Ecosystems, 5, 105-121, 2002.

Cotner, J. B., Makino, W., and Biddanda, B. A.: Temperature affects stoichiometry and biochemical composition of Escherichia coli, Microb. Ecol., 52, 26-33, 2006.

Craig, H. and Gordon, L. I.: Deuterium and 18 oxygen variations in the ocean and the marine atmosphere, in: Proceedings of a conference on stable isotopes in oceanographic studies and paleotemperatures, edited by: Tongiori, E., V. Lischi and sons, Pisa, 1965.

Dawson, P. S. S.: Microbial growth, Dowden, Hutchinson \& Ross, Stroudsburg, 1974.

del Giorgio, P. A. and Cole, J. J.: Bacterial growth efficiency in natural aquatic systems, Annu. Rev. Ecol. Syst., 29, 503-541, 1998.

Dijkstra, F. A., Hobbie, S. E., Knops, J. M. H., and Reich, P. B.: Nitrogen stabilization and plant species interact to influence soil carbon stabilization, Ecol. Lett., 7, 1192-1198, 2004.

Dijkstra, P., Thomas, S. C., Heinrich, P. L., Koch, G. W., Schwartz, E., and Hungate, B. A.: Effect of temperature on metabolic 
activity of intact microbial communities: evidence for altered metabolic pathway activity but not for increased maintenance respiration and reduced carbon use efficiency, Soil Biol. Biochem., 43, 2023-2031, 2011.

Egli, T.: Microbial growth and physiology: a call for better craftsmanship, Front. Microbiol., 6, 287, doi:10.3389/fmicb.2015.00287, 2015.

El-Mansi, E. M. T. and Holms, W. H.: Control of carbon flux to acetate excretion during growth of Escherichia coli in batch and continuous cultures, J. General Microbiol., 135, 2875-883, 1989.

Farquhar, G. D., and Richards, R. A.: Isotopic composition of plant carbon correlates with water-use efficiency of wheat genotypes, Aust. J. Plant Physiol., 11, 539-552, 1984.

Farquhar, G. D., O'Leary, M. H., and Berry, J. A.: On the relationship between carbon isotope discrimination and the intercellular carbon dioxide concentration in leaves, Aust. J. Plant Physiol., 9, 121-137, 1982.

Ferenci, T.: Bacterial physiology, regulation and mutational adaptation in a chemostat environment, Adv. Microb. Physiol., 53, 169-230, 2008.

Fernandez, I. and Cadisch, G.: Discrimination against ${ }^{13} \mathrm{C}$ during degradation of simple and complex substrates by two white rot fungi, Rapid Commun. Mass Sp., 17, 2614-2620, 2003.

Frey, S., Lee, J., Melillo, J. M., and Six, J.: The temperature response of soil microbial efficiency and its feedback to climate, Nature Climate Change, 3, 395-398, 2013.

Fry, B.: Stable Isotope Ecology, Springer, New York, 2006.

Gamnitzer, U., Moyes, A. B., Bowling, D. R., and Schnyder, H.: Measuring and modelling the isotopic composition of soil respiration: insights from a grassland tracer experiment, Biogeosciences, 8, 1333-1350, doi:10.5194/bg-8-1333-2011, 2011.

Ghashghaie, J. and Badeck, F. W.: Opposite carbon isotope discrimination during dark respiration in leaves versus roots - a review, New Phytol., 201, 751-769, 2014.

Gillooly, J. F., Brown, J. H., West, G. B., Savage, V. M., and Charnov, E. L.: Effects of size and temperature on metabolic rate, Science, 293, 2248-2251, 2001.

Gleixner, G. and Schmidt H.-L.: Carbon isotope effects on the Fructose-1,6-bisphosphate aldolase reaction, origin for nonstatistical ${ }^{13} \mathrm{C}$ distributions in carbohydrates, J. Biol. Chem., 272, 5382-5387, 1997.

Goldman, J. C. and Dennet, M. R.: Growth of marine bacteria in batch and continuous culture under carbon and nitrogen limitation, Limnol. Oceanogr., 45, 789-800, 2000.

Hall, E. K., Neuhauser, C., and Cotner, J. B.: Toward a mechanistic understanding of how natural bacterial communities respond to changes in temperature in aquatic ecosystems, ISME J., 2, 471481, 2008.

Hanson, P. J., Edwards, N. T., Garten, C. T., and Andrews, J. A.: Separating root and microbial contributions to soil respiration: a review of methods and observations, Biogeochemistry, 48, 115146, 2000.

Hedges, J. I., Eglinton, G., Hatcher, P. G., Kirchman, D. L., Arnosti, C., Derenne, S., Evershed, R. P., Kögel-Knabner, I., de Leeuw, J. W., Littke, R., Michaelis, W., and Rullkötter, J.: The molecularlyuncharacterized component of nonliving organic matter in natural environments, Org. Geochem., 31, 945-958, 2000.

Hobbie, J. E. and Hobbie, E. A.: Microbes in nature are limited by carbon and energy: the starving-survival lifestyle in soil and consequences for estimating microbial rates, Front. Microbiol., 4, 324, doi:10.3389/fmicb.2013.00324, 2013.

Kayser, A., Weber, J., Hecht, V., and Rinas, U.: Metabolic flux analysis of Escherichia coli in glucose-limited continuous culture. I. Growth-rate dependent metabolic efficiency at steady-state, Microbiology, 151, 693-706, 2005.

Kirschbaum, M. U. F.: The temperature-dependence of organicmatter decomposition - still a topic of debate, Soil Biol. Biochem., 38, 2510-2518, 2006.

Klumpp, K., Schäufele, R., Lötscher, M., Lattanzi, F. A., Feneis, W., and Schnyder, H.: C-isotope composition of $\mathrm{CO}_{2}$ respired by shoots and roots: fractionation during dark respiration?, Plant Cell Environ., 28, 241-250, 2005.

Kucera, C. L. and Kirkham, D. R.: Soil respiration studies in tallgrass prairie in Missouri, Ecology, 52, 912-915, 1971.

Lehmeier, C. A., Min, K., Niehues, N. D., Ballantyne IV, F., and Billings, S. A.: Temperature-mediated changes of exoenzymesubstrate reaction rates and their consequences for the carbon to nitrogen flow ration of liberated resources, Soil Biol. Biochem., 57, 374-382, 2013.

Manzoni, S., Taylor, P., Richter, A., Porporato, A., and Ågren, G. I.: Environmental and stoichiometric controls on microbial carbonuse efficiency in soils, New Phytol., 196, 79-91, 2012.

Min, K., Lehmeier, C. A., Ballantyne, F., Tatarko, A., and Billings, S. A.: Differential effects of $\mathrm{pH}$ on temperature sensitivity of organic carbon and nitrogen decay, Soil Biol. Biochem., 76, 193200, 2014.

Mook, W. G., Bommerson, J. C., and Staverman, W. H.: Carbon isotope fractionation between dissolved bicarbonate and gaseous carbon dioxide, Earth Planet. Sc. Lett., 22, 169-176, 1974.

Nanchen, A., Schicker A., and Sauer U.: Nonlinear dependency of intracellular fluxes on growth rate in miniaturized continuous cultures of Escherichia coli, Appl. Environ. Microb., 73, 1164$1172,2006$.

Nickerson, N., Egan, J., and Risk, D.: Iso-FD: A novel method for measuring the isotopic signature of surface flux, Soil Biol. Biochem., 62, 99-106, 2013.

O'Leary, M. H.: Carbon isotope fractionation in plants, Phytochemistry, 20, 553-567, 1981.

Park, R. and Epstein, S.: Metabolic fractionation of $\mathrm{C}^{13} \& \mathrm{C}^{12}$ in plants, Plant Physiol., 36, 133-138, 1961.

Pataki, D. E., Ehleringer, J. E., Flanagan, L. B., Yakir, D., Bowling, D. R., Still, C. J., Buchmann, N., Kaplan, J. O., and Berry, J. A.: The application and interpretation of Keeling plots in terrestrial carbon cycle research, Global Biogeochem. Cy., 17, 1022, doi:10.1029/2001GB001850, 2003.

Pomeroy, L. R. and Wiebe, W. J.: Temperature and substrate as interactive limiting factors for marine heterotrophic bacteria, Aquat. Microb. Ecol., 23, 187-204, 2001.

Rivkin, R. B. and Legendre, L.: Biogenic carbon cycling in the upper ocean: effects of microbial respiration, Science, 291, 23982400, 2001.

Rossmann, A., Butzenlechner, M., and Schmidt, H. L.: Evidence for a nonstatistical carbon isotope distribution in natural glucose, Plant Physiol., 96, 609-614, 1991.

Ŝantrůčková, H., Bird, M. I., and Lloyd, J.: Microbial processes and carbon-isotope fractionation in tropical and temperate grassland soils, Funct. Ecol., 14, 108-114, 2000. 
Schimel, D. S.: Terrestrial ecosystems and the carbon-cycle, Glob. Change Biol., 1, 77-91, 1995.

Smith, H. L. and Waltman, P. E.: The theory of the chemostat: dynamics of microbial competition, Cambridge University Press, New York, 1995.

Stumm, W. and Morgan, J. J.: Aquatic Chemistry: An introduction emphasizing chemical equilibria in natural waters, John Wiley \& Sons, New York, 1981.

Subke, J.-A., Inglima, I., and Cotrufo, M. F.: Trends and methodological impacts in soil $\mathrm{CO}_{2}$ flux partitioning: A metaanalytical review, Glob. Change Biol., 12, 921-943, 2006.

Szaran, J.: Achievement of carbon isotope equilibrium in the system $\mathrm{HCO}_{3}^{-}$(solution) - $\mathrm{CO}_{2}$ (gas), Chem. Geol., 142, 79-86, 1997.

Tcherkez, G., Mahé, A., and Hodges, M.: ${ }^{12} \mathrm{C} /{ }^{13} \mathrm{C}$ fractionations in plant primary metabolism, Trends Plant Sci., 16, 499-506, 2012.

Tempest, D. W. and Neijssel, O. M.: Eco-physiological aspects of microbial growth in aerobic nutrient-limited environments, Adv. Microb. Ecol., 2, 105-153, 1978.

Trumbore, S.: Carbon respired by terrestrial ecosystems - recent progress and challenges, Glob. Change Biol., 12, 141-153, 2006.

Tucker, C. L., Bell, J., Pendall, E., and Ogle, K.: Does declining carbon-use efficiency explain thermal acclimation of soil respiration with warming?, Glob. Change Biol., 19, 252-263, 2013.
Vogel, J. C., Grootes, P. M., and Mook, W. G.: Isotopic fractionation between gaseous and dissolved carbon dioxide, Z. Physik, 230, 225-238, 1970.

Werner, C. and Gessler, A.: Diel variations in the carbon isotope composition of respired $\mathrm{CO}_{2}$ and associated carbon sources: a review of dynamics and mechanisms, Biogeosciences, 8, 24372459, doi:10.5194/bg-8-2437-2011, 2011.

Werner, R. A., Buchmann, N., Siegwolf, R. T. W., Kornexl, B. E., and Gessler, A.: Metabolic fluxes, carbon isotope fractionation and respiration - lessons to be learned from plant biochemistry, New Phytol., 191, 10-15, 2011.

Werth, M. and Kuzyakov, Y.: ${ }^{13} \mathrm{C}$ fractionation at the rootmicroorganisms-soil interface: a review and outlook for partitioning studies, Soil Biol. Biochem., 42, 1372-1384, 2010.

Wieder, W. R., Bonan, G. B., and Allison, S. D.: Global soil carbon projections are improved by modelling microbial processes, Nature Climate Change, 3, 909-912, 2013.

Wittmann, C., Weber, J., Betiku, E., Krömer, J., Böhm, D., and Rinas, U.: Response of fluxome and metabolome to temperatureinduced recombinant protein synthesis in Escherichia coli, J. Biotechnol., 132, 375-384, 2007. 